\title{
The Effectiveness of a Formal Physical Education Curriculum on the Physical Ability of Children in a Preschool Context
}

\author{
Carol Boon Peng Loy-Ee ${ }^{1, *} \&$ Patricia Mui Hoon $\mathrm{Ng}^{2}$ \\ ${ }^{1}$ Early Childhood Curriculum Department, Kinderland Educare Services, Singapore \\ ${ }^{2}$ Register of Educational Therapists (Asia), Singapore \\ *Correspondence: Kinderland Educare Services, 87 Marine Parade Central, Singapore 440087. Tel: 65-6342-5600. \\ E-mail: carol.loy@kinderland.com.sg
}

Received: December 28, 2017

Accepted: January 3, 2018 Online Published: January 17, 2018

doi:10.5430/jct.v7n1p13

URL: https://doi.org/10.5430/jct.v7n1p13

\begin{abstract}
Studies have pointed to the benefits of physical activity (PA), yet the level of PA participation among preschoolers is low. This in turn could have resulted in the limited research literature on the PA level or physical education curriculum (PEC) of preschool children. Those reviewed here are mostly from countries in the West, as those from Asia are unavailable. To fill this gap, the present study was carried out to investigate the effectiveness of a formal PEC on the physical ability of a sample of five-year old children from several preschools in Singapore. Using a Physical Ability Assessment (PAA) tool with five variables, a pre-test/post-test quasi-experimental design was used to measure the effectiveness of the PEC with control and experimental groups for the comparative analysis. The results of the PAA are presented and the implications from the findings and analysis are discussed.
\end{abstract}

Keywords: physical activity; preschool children; comparison study; physical education curriculum

\section{Introduction}

\subsection{Physical Activity in Preschoolers}

The issue of low levels of PA in preschoolers has been of concern for some advanced countries outside of Asia that even their policy-makers pay attention to it. According to a review of 39 studies by Tucker (2008) on the levels of physical activity of preschool-aged children, a majority of the reports have indicated that the physical activity level of such children is below the guideline set by the American Alliance for Health, Physical Education, Recreation and Dance (AAHPERD). This was set at $60 \mathrm{~min}$ of structured and a minimum of $60 \mathrm{~min}$ of unstructured physical activity per day (National Association for Sport and Physical Education, 2002). Only 23\% of the studies in this review reported PA levels that met the guideline. In the new guidelines released in Australia (Australian Government, Department of Health \& Ageing, 2010), the United Kingdom (Department of Health, 2011), and Canada (Tremblay et al., 2012), the minimum level is increased to $180 \mathrm{~min}$ of PA per day (at any intensity). Hence, it is likely to be even harder to find evidence where preschoolers' PA levels met the higher new criteria. Without intervention, the level of participation in PA among preschoolers is unlikely to increase.

\subsection{Benefits of Physical Activity or Physical Education Curriculum}

Many health benefits have been associated with physical activity (PA) engagement as it helps to prevent children and youth from developing chronic conditions (Hinkley, Crawford, Salmon, Okely, \& Hesketh, 2008) such as Type II diabetes, cardiovascular disease, hypertension, dyslipidemia, sleep apnea, gastrointestinal problems, depression (Daniels, 2006; Reilly, 2005; Strong et al., 2005), and obesity (Marcus et al., 2000; Sturm, 2005). Over and above this, there is mounting evidence linking motor skills and PA to not merely healthy physical development but that of cognitive, emotional and social development as well during early childhood (Timmons, Naylor, \& Pfeiffer, 2007). For instance, a positive relationship has been found between physical education and academic achievements in the large scale studies conducted by the California Department of Education (2002), Tomporowski (2003) and Grissom (2005).

In the 2002 research study carried out by the California Department of Education, 954,000 students were involved. 
The students' academic scores in this study were matched with their physical fitness tests results and a distinct relationship between physical fitness and academic achievement was found. The conclusion drawn for the study is that higher academic scores are associated with higher level of fitness at each of the grade level of the students involved (California Department of Education, 2002). In another study, Sibley \& Etnier (2003) found that fitness training or PA incorporated within the school environment is likely to improve cognitive performance. With respect to more specific variables related to cognitive development, a study by Hillman, Castelli, \& Buck (2005) showed that there are positive effects of PA on attention and concentration.

Despite an abundance of evidence pointing to the benefits of PA, such activities in the school curriculum can be frequently overshadowed or marginalized by the importance of academic subjects. This is especially so in many Asian societies, due to a huge emphasis on academic achievement from childhood (Yu, Chan, Cheng, Sung, \& Hau, 2006). Leong \& Fry (2013) had pointed out that Singapore has an education system where academic excellence prevails; hence Singapore would likely not be an exception to this phenomenon. Although this is more likely to happen during the primary to secondary school years (Coe, Pivarnik, Womack, Reeves, \& Malina, 2006), it might not be surprising to find the marginalization of PA or physical education curriculum (PEC) in the name of raising pupils' academic performance even in the preschool years.

Without using a top-down approach to change mindsets, parents, other than educators, might be won over through other benefits of providing PA or PEC for young children. According to Stojanović, Pavlović, \& Stojanović (2012), the purpose of a PEC as an organized process of education is to create a positive influence on the psycho-somatic status of schoolchildren. The transformations in the somatic status would then rectify the effect of biological factors that have been deemed insufficient during the intensified period of growth and development in childhood. Furthermore, as suggested by Prosser \& Jiang (2008), habits of regular exercise and PA developed in early childhood are likely to carry on in later childhood and further into adolescence. Therefore, early childhood is a critical period for the establishment of regular exercise and PA habits in order to reap such health and lifestyle benefits.

\subsection{Review on Studies}

Beyond just regular exercise and PA habits, several researchers (Gallahue \& Ozmun, 2006; Stodden et al., 2008) have conducted studies to find out more on the development of fundamental motor skills (FMS) in the preschool years. FMS such as walking, running, jumping, throwing, catching and kicking belong in the categories of balance, locomotor and manipulative skills according to their character and quality (Gallahue \& Ozmun, 2006). They also stressed that the early years are especially vital for the development of FMS, as it lays the foundation for a physically active lifestyle in a child's later years. Since spending time on PA alone may not suffice in generating improvements in preschool children's FMS, training in specific skills would be necessary for the achievement of such outcomes (Deli et al., 2006; Zachopoulou, Tsapakidou, \& Derri, 2004). Hence, the PEC intervention of the present study incorporates FMS in order to fill the gap for the achievement of such beneficial outcomes.

According to Gallahue \& Cleland-Donnelly (2003), a developmentally appropriate PEC is grounded on motor development and skill learning in the setting of games, dance and gymnastics, and on the notions of movement, skill and activity. Educators are therefore urged to be familiar with the relationships between the movements in the tasks, the biological makeup of the child, as well as the context of the environment for learning (Gagen \& Getchell, 2006). With this knowledge, they would be able to ensure that the choice of tasks, equipment and environment interact (Ministry of Social Affairs and Health, 2005). This is another important underpinning of the PEC intervention in the present study.

Studies on the effects of PA or PEC for young children in Asia are hard to come by. On the other hand, several studies can be found in the west. For example, a study by Deli, Bakle, \& Zachopoulou (2006) on movement programmes for kindergarten children had found that the 10 -week movement programme was significantly related to the locomotor skills of the five-year-old subjects. In Norway, a study by Fjortoft (2001) showed that the five- to seven-year-old Norwegian preschool subjects improved in their balance and locomotor skills with a PE programme that simply consisted of playing in a natural environment playground.

In another Nordic country - Finland, findings from a study by Sääkslahti et al. (1999) revealed that there was a positive relationship between a three-year family-based physical activity intervention and the locomotor skills of four-year-old Finnish children. However, one of the variables - manipulative skills, was found to be unrelated to the intervention. This finding highlights the challenges in using movement programmes to achieve the desired positive outcomes. Sääkslahti et al. (1999) have mentioned that this is attributed to the dynamic nature of motor development. Much can therefore be learnt from past research for the potential limitations in the present study. 


\subsection{Hypotheses and Research Design}

While the knowledge-sharing from previous research done provides guidance, the present study is carried out in view of the want of research studies on the PA level or PEC of preschool children in Asia to fill the gap. A pre-test/post-test quasi-experimental design was used to measure the effectiveness of the intervention with a sample of 5-year old children from several preschools in Singapore. For comparison purposes, control and experimental groups were used for the analysis. Independent samples t-tests were conducted to find out if there are any significant differences in the outcomes of the PEC between the control and experimental groups. The results of the tests were analyzed to find out if the experimental group performed better than the control group at post-test.

The intervention of the present study comprised 20 weeks of formal PEC in the preschools involved. In the intervention, the subjects undertook activities where FMS such as walking, running, jumping, kicking, throwing and catching in the categories of locomotor, balance and manipulative skills were involved. Grounded on motor development and skill learning, the PEC was customized to be developmentally appropriate through the setting of dance, games and gymnastics, and on the concepts of skill, movement and activity. The instructors were trained to be familiar with the relationships between the biological makeup of the child-subjects, the movements in the tasks, and the context of the environment for learning as well. Hence, they were able to ensure that the choice of environment, tasks and equipment interacted, so as to pique the children's interest and keep them engaged. The aim of the intervention program was to show that a well-planned PEC can be used as an efficient educational approach to facilitate the development of physical abilities. In doing so, it was also hoped that active learning through physical movement with FMS can be promoted, and a positive attitude towards a healthy lifestyle could be instilled as well. To measure the effectiveness of the intervention, a Physical Ability Assessment (PAA) tool with five variables (Maehashi, 2010) tried and tested on preschoolers in Japan was used.

\section{Method}

\subsection{Participant Characteristics}

In the present study, the subjects were recruited by convenience sampling. Following the interest to participate and consent from the children and their parents, data on the age and gender of the subjects was collected.

Table 1. Gender Distribution (\%)

\begin{tabular}{ccccc}
\hline Gender & Frequency & Percent & Valid Percent & Cumulative Percent \\
\hline Male & 28 & 56 & 56 & 56 \\
Female & 22 & 44 & 44 & 100 \\
Total & 50 & 100 & 100 & \\
\hline
\end{tabular}

Table 2. Age Statistics (months) on 1st Jan 2015

\begin{tabular}{ccccccccc}
\hline Variable & $\mathrm{N}$ & Mean & Mode & Std. Deviation & Variance & Range & Minimum & Maximum \\
\hline Group & 50 & 53.72 & 57 & 3.40 & 11.55 & 11 & 48 & 59 \\
\hline
\end{tabular}

Table 1 above shows the gender distribution data of the sample. The age profile of the sample is shown in Table 2 . The total number of subjects was 50, which more than sufficiently met the recommendations by Creswell (2012) for the sample size of 15 participants for a group experimental design. Moreover, this larger sample size as according to Creswell (2012) would have the advantage of reducing the potential of sampling error.

\subsection{Procedures}

The subjects were assigned to two groups at the start of the study. Those from childcare centers offering the PEC were assigned to the experimental group $(n=25)$ which received the intervention; while those from preschools that do not offer the PEC were assigned to the control group $(n=25)$. The two groups have similar gender ratios and age. They generally shared the same socioeconomic background (i.e. middle class) in demographical characteristics as well.

\subsubsection{Pre-test Measures}

Pre-tests using the Physical Ability Assessment tool were carried out at the beginning of the intervention program to determine the baseline performance for comparison with post-tests performance at the end of the intervention. To determine if the two groups were comparable at baseline in terms of the Physical Ability Assessment items, 
independent t-tests were carried out on the null hypotheses in the following:

- There are no significant differences between the experimental and control groups' Physical Ability Assessment items' pre-test means.

\subsubsection{Post-test measures}

Post-tests were carried out at the end of the intervention program for comparison of the groups' performance. To determine if there are significant differences between the two groups' performance at post-test, independent t-tests were carried out on the null hypotheses in the following:

- There are no significant differences between the experimental and control groups' Physical Ability Assessment items' post-test means.

\section{Results}

\subsection{Pre-test Measures}

Table 4. Pre-test Means

\begin{tabular}{|c|c|c|c|c|c|c|c|c|c|}
\hline 1:Exp; 2:Con & Grip - Pre & Crawl & - Pre & Run & - Pre & Jump & - Pre & Toss & - Pre \\
\hline Mean 1 & 9.30 & & 30.19 & & 8.15 & & 76.48 & & 3.88 \\
\hline Mean 2 & 11.16 & & 45.35 & & 7.91 & & 71.00 & & 3.88 \\
\hline Means Difference & -1.87 & & -15.16 & & 0.24 & & 5.48 & & 0.00 \\
\hline
\end{tabular}

Table 4 shows the results of the pre-test means of the Physical Ability Assessment variables and means differences of the two comparison groups. The control group did better at the Grip and Run tests but was behind the experimental group at the Crawl and Jump tests. Independent t-tests of pre-test means differences were carried out to see if these differences were significant.

Table 5. Summary of Pre-test Means Differences

\begin{tabular}{cclc}
\hline $\begin{array}{c}\text { Item } \\
\text { no. }\end{array}$ & $\begin{array}{c}\text { Group } \\
\text { Variable }\end{array}$ & \multicolumn{1}{c}{ Independent t-test of group means difference } & $\begin{array}{c}\text { Significant } \\
\text { Difference? }\end{array}$ \\
\hline 1 & Grip - Pre & Mean Difference $=1.87 ; \mathrm{t}(48)=-2.96,95 \%$ C.I. -3.14, -0.60) & Yes \\
2 & Crawl - Pre & Mean Difference $=15.16 ; \mathrm{t}(48)=-2.62,95 \%$ C.I. -26.78, -3.55) & No \\
3 & Run - Pre & Mean Difference $=0.24 ; \mathrm{t}(48)=1.02,95 \%$ C.I. - $0.24,0.72)$ & No \\
4 & Jump - Pre & Mean Difference $=5.48 ; \mathrm{t}(48)=1.05,95 \%$ C.I. $-5.05,16.01)$ & Yes \\
5 & Toss - Pre & Mean Difference $=0.00$ & No \\
\hline
\end{tabular}

The hypothesis testing results in Table 5 above show that the two groups are comparable in their levels of performance in the Crawl, Run and Toss items at pre-test. Significant differences were found in the Grip and Jump variables, where the control group was already ahead at the Grip test but was behind the experimental group at the Jump test. For the Grip test, the significant difference at the start would mean that the experimental group, which is already behind, would need a larger amount of improvement after the intervention in order to achieve a significant difference for the post-test results. For the Jump test on the other hand, the experimental group may widen their lead after the intervention.

\subsection{Post -test Measures}

Table 6. Post-test means

\begin{tabular}{|c|c|c|c|c|c|c|c|c|c|}
\hline 1:Exp; 2:Con & Grip - Post & Crawl & - Post & Run & - Post & Jump & - Post & Toss & - Post \\
\hline Mean 1 & 11.46 & & 20.43 & & 7.33 & & 97.36 & & 4.79 \\
\hline Mean 2 & 11.44 & & 26.33 & & 7.41 & & 89.36 & & 4.60 \\
\hline Means Difference & 0.02 & & -5.90 & & -0.08 & & 8.00 & & 0.18 \\
\hline
\end{tabular}

Table 6 above shows the results of the post-test means of all the test variables and means differences of the two comparison groups. The post-test results show that the experimental group had performed better than the control 
group in all the physical ability test items (Grip, Crawl, Run, Jump and Toss). Specifically, the experimental group did better than the control by $0.02 \mathrm{~kg}$ for the Grip test, $5.9 \mathrm{~s}$ for the Crawl, $0.08 \mathrm{~s}$ for the Run, $8 \mathrm{~cm}$ for the Jump and $0.18 \mathrm{~m}$ for the Toss.

Table 7. Summary of Post-test Means Difference Independent t-test

\begin{tabular}{cclc}
\hline $\begin{array}{c}\text { Item } \\
\text { no. }\end{array}$ & $\begin{array}{c}\text { Group } \\
\text { Variable }\end{array}$ & \multicolumn{1}{c}{ Independent t-test of group means difference } & $\begin{array}{c}\text { Significant } \\
\text { Difference? }\end{array}$ \\
\hline 1 & Grip - Post & Mean Difference $=0.02 ; \mathrm{t}(48)=-0.04,95 \%$ C.I. $-1.06,1.11)$ & Yes \\
2 & Crawl - Post & Mean Difference $=-5.90 ; \mathrm{t}(48)=-3.40,95 \%$ C.I. $-9.38,-2.42)$ & Yes \\
3 & Run - Post & Mean Difference $=-0.08 ; \mathrm{t}(48)=-0.36,95 \%$ C.I. $-0.56,0.39)$ & Yes \\
4 & Jump - Post & Mean Difference $=8.00 ; \mathrm{t}(48)=1.91,95 \%$ C.I. -0.40, 16.40) & Yes \\
5 & Toss - Post & Mean Difference $=0.18 ; \mathrm{t}(48)=0.49,95 \%$ C.I. $-0.57,0.94)$ & Yes \\
\hline
\end{tabular}

The hypothesis testing results of the post-test mean differences collated in Table 7 above show that the two groups have significantly different means in the physical assessment items 1-5. This implies that the experimental group had performed significantly better than the control group in all the physical ability test items (Grip, Crawl, Run, Jump and Toss).

\section{Discussion \& Conclusion}

From the results, it can be concluded that the Experimental group performed significantly better than the Control group in the physical ability tasks (Grip, Crawl, Run, Jump and Toss) at post-test.

Prior to the intervention at pre-test, significant differences were found where the control group was already ahead at the Grip test but was behind the experimental group at the Jump test. The significant differences found at post-test therefore showed that the experimental group had a much larger improvement than the control group, as the former had done better than the latter. For the Jump test on the other hand, the experimental group did better by $8 \mathrm{~cm}$, widening their lead after the intervention, as the pre-test difference was only $5.48 \mathrm{~cm}$. Hence, the significantly better means for the intervention group for all the physical ability test items at post-test provide the evidence that the intervention is effective.

The present study therefore contributes to a limited pool of research studies (e.g. Deli et al., 2006; Fjortoft, 2001; Sääkslahti et al., 1999) reviewed here which show that intervention can bring about better outcomes for the growth and development of preschool children. Even as the dynamic nature of motor development posed a limitation as manifested in the study by Sääkslahti et al. (1999), it was not the case in the present study. The implication is that a formal PEC can be used as an efficient educational approach to facilitate the development of physical abilities.

For replication purposes, it is highlighted here that the effects of the present study were validated by controlling the sample in terms of the similar profile in gender, age and socio-economic status to start with. To overcome the threat of distress to the subjects in a random group assignment, a quasi-experimental design was used. This helped to facilitate a more accurate measure of the children's true potential under their existing class groupings. Furthermore, the threat of participant mortality was controlled by using a sample size larger than the recommendation according to Creswell (2012) of fifteen subjects for a group experiment. In addition, maturational factors were overcome by using a control group which did not receive the intervention for the comparison.

As this is the first study carried out on the effect of a preschool PEC on children's physical ability in Singapore, further research is recommended to validate the effects for groups with dissimilar demographics. This is as research and testing can bring about empirical data for analysis and evaluation of programs. More importantly, it can help lend a voice to preschool children who are in need of PA in order to achieve better outcomes in their growth and development. Given the benefits of physical activities on early childhood and beyond, it is highly recommended that preschool children be given more opportunities to participate in various physical activities. It is even better to provide them with PEC, which can improve their FMS, psycho-somatic status and grow their love for PA throughout their life-span, so that they may reap the many health benefits that have been associated with PA as well.

\section{Acknowledgements}

The authors sincerely thank the participants and their parents for their consent to participate, as well as the staff from the preschools involved for their invaluable help in the research. Without their support, this study would not have 
been possible.

\section{References}

Australian Government, Department of Health and Ageing. (2010). Physical activity recommendations for children 0-5 years. Woden, ACT, Australia: Retrieved February 6, 2012, from http://www.health.gov.au/internet/main/publishing.nsf/content/health-pubhlth-strategphys-act-guidelines\#rec_0_ 5

California Department of Education. (2002). Physical fitness testing and SAT9. Retrieved 20 April, 2007, from http://www.cde.ca.gov/statetests/pe/pe.html.

Coe, D. P., Pivarnik, J. M., Womack, C. J., Reeves, M. J., \& Malina, R. M. (2006). Effects of physical education and activity levels on academic achievement in children. Medicine and Science in Sports and Exercise, 38(8), 1515-1519. https://doi.org/10.1249/01.mss.0000227537.13175.1b

Daniels, S. R. (2006). The consequences of childhood overweight and obesity. The Future of Children, 16, 47-67. https://doi.org/10.1353/foc.2006.0004

Deli, E., Bakle, I., \& Zachopoulou, E. (2006). Implementing intervention movement programs for kindergarten children. Journal of Early Childhood Research, 4, 5-18. https://doi.org/10.1177/1476718X06059785

Department of Health (2011). Start active, stay active: A report on physical activity for health from the four home countries' chief medical officers. London, UK: Retrieved February 6, 2012, from http://www.gov.uk/government/uploads/system/uploads/attachment_data/file/216370/dh_128210.pdf

Fjortoft, I. (2001). The natural environment as a playground for children: The impact of outdoor play activities in pre-primary school children. Early Childhood Education Journal, 29, 111-117. https://doi.org/10.1023/A:1012576913074

Gagen, L.M., \& Getchell, N. (2006). Using 'constraints' to design developmentally appropriate movement activities for early childhood. Early Childhood Education Journal, 34, 227-232. https://doi.org/10.1007/s10643-006-0135-6

Gallahue, D.L., \& Cleland-Donnelly, F. (2003). Developmental physical education for all children. Champaign, IL: Human Kinetics.

Gallahue, D.L., \& Ozmun, J.C. (2006). Understanding motor development: Infants, children, adolescents, adults. Boston: McGraw-Hill.

Grissom, J. B. (2005). Physical fitness and academic achievement. Journal of Physical Online, 8(1), 11-25. Retrieved 20 August, 2010, from http://www.asep.org/files/Grissom.pdf.

Hillman, C. H., Castelli, D. M., \& Buck, S. M. (2005). Aerobic fitness and neurocognitive function in healthy preadolescent children. Medicine \& Science in Sports \& Exercise, 37, 1967-1974. https://doi.org/10.1249/01.mss.0000176680.79702.ce

Hinkley, T., Crawford, D., Salmon, J., Okely, A. D., \& Hesketh, K. (2008). Preschool children and physical activity-A review of correlates. American Journal of Preventive Medicine, 34, 435-441. https://doi.org/10.1016/j. amepre.2008.02.001

Leong, L., \& Fry, J. M. (2013). Young Singaporeans' Perceptions on Dance in Physical Education. In C.-H. Lum (Ed.), Contextualized Practices in Arts Education: An International Dialogue on Singapore (pp. 113-131). Singapore: Springer Singapore.

Maehashi, A. (2010). The relations between physical vitality and sleeping of today's preschoolers. The Journal of Physical Education of Young Children of Asia, 1, 13-22.

Marcus, B. H., Dubbert, P. M., Forsythe, L. H., McKenzie, T. L., Stone, E. J., Dunn, A. L., \& Blair, S. (2000). Physical activity behavior change: Issues in adoption and maintenance. Health Psychology, 19, 32-41. https://doi.org/10.1037/0278-6133.19.Supp11.32

Ministry of Social Affairs and Health. (2005). Recommendations for physical activity in early childhood education. Helsinki: Brochures of the Ministry of Social Affairs and Health 2005, 17.

National Association for Sport and Physical Education. (2002). Active start: A statement of physical activity guidelines for children birth to 5 years. Oxon Hill, MD: AAHPERD Publications. 
Prosser, L., \& Xiaoli, J. (2008). Relationship between School Physical Activity and Academic Performance of Children. International Journal of Learning, 15, 11-16. https://doi.org/10.18848/1447-9494/CGP/v15i03/45649

Reilly, J. J. (2005). Descriptive epidemiology and health consequences of childhood obesity. Best Practice \& Research Clinical Endocrinology \& Metabolism, 19, 327-341. https://doi.org/10.1016/j.beem.2005.04.002

Sääkslahti, A., Numminen, P., Niinikoski, H., Rask-Nissilä, L., Viikari, J., Tuominen, J., et al. (1999). Is physical activity related to body size, fundamental motor skills, and CHD risk factors in early childhood? Pediatric Exercise Science, 11, 327-340. https://doi.org/10.1123/pes.11.4.327

Sibley, B. A., \& Etnier, J. L. (2005). The relationship between physical activity and cognition in children: A meta-analysis. Pediatric Exercise Science, 15, 243-256. https://doi.org/10.1123/pes.15.3.243

Stodden, D.F., Goodway, J.D., Langendorfer, S.J., Stephen, J., Roberton, M.A., Rudisill, M.E., et al. (2008). A developmental perspective on the role of motor skill competence in physical activity: An emergent relationship. Quest, 60, 290-306. https://doi.org/10.1080/00336297.2008.10483582

Stojanović, N., Pavlović, R., \& Stojanović, D. (2012). The effects of sports activities classes in the physical education curriculum. Acta Kinesiologica, 6, 31-36.

Strong, W. B., Malina, R. M., Blimkie, C. J. R., Daniels, S. R., Dishman, R. K., Gutin, B., \& . . Trudeau, F. (2005). Evidence-based physical activity for school-aged youth. Journal of Pediatrics, 146, 732-737. https://doi.org/10.1016/j.jpeds.2005.01.055

Sturm, R. (2005). Childhood obesity - what we can learn from existing data on societal trends, Part 1. Preventing Chronic Disease: Public Health Research, Practice, and Policy, $2, \mathrm{~A} 12$.

Timmons, B. W., Naylor, P. J., \& Pfeiffer, K. A. (2007). Physical activity for preschool children-How much and how? Applied Physiology, Nutrition, and Metabolism, 32(Suppl .2E), S122-S134. https://doi.org/10.1139/H07-112

Tomporowski, P. (2003). Cognitive and behavioral responses to acute exercise in youths: A review. Pediatric Exercise Science, 15, 348-359. https://doi.org/10.1123/pes.15.4.348

Tremblay, M. S., LeBlanc, A. G., Carson, V., Choquette, L., Connor Gorber, S., Dillman, C., . . Timmons, B. W. (2012). Canadian physical activity guidelines for the early years (aged 0-4 years). Applied Physiology, Nutrition, and Metabolism, 37, 345-356. https://doi.org/10.1139/h2012-018

Tucker, P. (2008). The physical activity level of preschool-aged children: A systematic review. Early Childhood Research Quarterly, 23, 547-558. https://doi.org/10.1016/j.ecresq.2008.08.005

Yu, C. C. W., Chan, S., Cheng, F., Sung, R. Y. T., \& Hau, K. T. (2006). Are physical activity and academic performance compatible? Academic achievement, conduct, physical activity and self-esteem of Hong Kong Chinese primary school children. Educational studies, 32, 331-341. https://doi.org/10.1080/03055690600850016

Zachopoulou, E., Tsapakidou, A., \& Derri, V. (2004). The effects of a developmentally appropriate music and movement program on motor performance. Early Childhood Research Quarterly, 19, 631-642. https://doi.org/10.1016/j.ecresq.2004.10.005 